\title{
A Survey of Cohesion in the Editorials of the Punch and Vanguard Newspapers
}

\author{
Esther Robert \\ Department of English,University of Uyo, Akwa Ibom,Nigeria
}

\begin{abstract}
This work analysed patterns of cohesion as are employed by the writers of the editorials of The Punch and Vanguard newspapers. The basic purpose of the study was to investigate how English cohesive devices are exploited in textual creations and how they aid in meaning comprehension. For the purpose of the analysis, fourteen editorial comments from The Punch and Vanguard newspapers were purposively sampled from the period of June to August, 2016. Halliday and Hasan's (1976) model of cohesion was adopted as the theoretical framework. Both qualitative and quantitative methods were used for the analysis. This framework revealed the agglutinating effect of cohesive devices that contribute greatly to the creation of semantic understanding of the texts, especially the concepts of referencing, ellipsis, conjunction, substitution, reiteration and collocation as text-making devices through which the different parts of a text are knitted together as a whole. The study showed how these devices were utilised in the newspaper editorials studied. The analysis revealed that for a text to be cohesive, it must be held together by some grammatical and lexical devices. Two main types of cohesion were found in the editorial commentaries, viz reiteration and collocation. The quantitative analysis revealed that sameword repetition had the highest percentage $(22.37 \%)$ of deployment in the editorial creation, while general-word reiteration type was least deployed in the texts studied, with only $1.31 \%$. In the case of collocation device, its usage amounted to $42.06 \%$. These devices ultimately contributed to clarifying the overall meaning of the different texts by binding them together, emphasizing central ideas and giving a sense of connection and order to meaning and ideas within the texts. Therefore, without cohesive devices in a text, there will be no cohesion and coherence. Further investigation on other standards of textuality, in both literary and non literary texts, was recommended. Patterns of cohesion should be introduced in the English curriculum.
\end{abstract}

Keywords: cohesion, editorials, The Punch and Vanguard newspapers

DOI: $10.7176 / \mathrm{NMMC} / 82-01$

Publication date: August $31^{\text {st }} 2019$

\subsection{Introduction}

This study examines the ways cohesion, as a discourse strategy, is used in The Punch and Vanguard newspapers in the creation of textual bond. It has it basis on text linguistics. Text linguistics is an important aspect of linguistic studies that has engaged the attention of scholars since early 1970s. It is, in general, an application of discourse analysis in a much broader level of text, rather than just a sentence or word. It shifts focus away from the analysis of sentences as a self-contained unit to the analysis of how sentences are equally used in connected stretches of language (text) (Paltridge, 2006).

Olaniyan (2011) opines that linguistic analysis should no longer be limited to sentence-level analysis but should extend to cover the way sentences work in sequence to produce coherent stretches of utterances referred to as discourse or text. On this note, Paltridge (2006: pl27) observes that "in recent years, discussions of grammar have moved from sentence-based perspective to a larger whole of discourse". Such analysis, by implication, highlights the fact that a number of linguistic items such as "it", "that" and "this" assume different patterns of use when looked at from a discourse rather than sentence perspective.

Scholars over time have come up with certain standards a text is expected to meet before it can mean anything to the receiver. For instance, de Beaugrande and Dressier as cited in Wang and Quo (2014) proposed seven standards of textuality that a text must satisfy. According to them, one of such standards is cohesion. Paltridge (2006) explicates that patterns of cohesion are further ways in which unity of texture is achieved in a text. Unity of texture manifests where there are language items that tie meanings together in the text. Osisanwo (2003) explains that cohesion in text or discourse has to do with how actual texts are held together lexically and grammatically.

It therefore becomes pertinent to examine the extent to which cohesive devices work to make the editorial comments of national newspapers meaningful and coordinated to the reader, and also investigates how cohesive ties enhance the texture of the editorial texts. This is because newspapers, as opined by Esimokha (201 1:p2), is "...more than just sheets of paper lined with ink. Their production holds much greater significance than providing profits for the publisher... in all countries of the world; the newspaper has come to occupy a prime place in the social, economic and political realm". Embedded in Esimokha's conjecture is the idea that the basic functions of newspapers are to educate, inform, entertain and interpret.

Generally, writers of editorial comments aim at commenting on a current subject matter or presenting a 
particular point of view or opinion on a topic of current interest to the readers. Since they are meant for public consumption, they are naturally expected to meet the standard of text creation. A text, as explained by Bloor and Bloor (2004:p5), "...is any stretch of language, regardless of length that is spoken or written for the purposes of communication by real people in actual circumstances" and not necessarily a single unit of the sentence. Following a similar analysis, Tas, as cited in Hameed (2008:p82), highlights the fact that, as a means of communication, texts play very important role in getting meaning across to others. Tas insists that "no matter what type it might be, every text ought to address certain receivers who read it for a specific purpose like to get information, to read for fun, etc." These explanations are typical of editorials of national dailies. This is because newspapers are known to address general issues that are often of interest to the masses. Generally, important pieces of information about different domains of the society are often circulated through the newspapers.

Considering such vital roles newspapers play in the lives of the readers, attention ought to be paid to the make-up of the discourse in them. Linguistic items such as English cohesive devices should be employed to enrich their texture since the texts under consideration employ the English language as the medium of expression. This research has as its central goal to determine the richness of the editorial texts with cohesive devices and to assess whether editorial writers have utilized the linguistic effects of patterns of cohesion.

Furthermore, the various uses of language to present ideas, disseminate information, convey opinion, among others, are considered very rich resources for linguistic analysis. Meanwhile, researches have been carried out on language use on news headlines (Tabe and Fieze, 2018; Montejo and Adriano, 2018), political speeches (Schaffner, 2010), television commentaries (Kaleta, 2012) billboard adverts (Maalej, 2015) and editorial comments at various levels of linguistic analysis. However, our choice of newspaper editorial is to further enrich scholarly researches on meaning investigation in non-literary texts owing to the observation of $\mathrm{Xi}$ (2010:p143) that "the study of cohesive devices in non-literary texts is still a neglected area which needs further explorations". Our interest in this research is primarily to find out if editorial comments of national dailies are rich in the employment of cohesive devices and equally consider the extent to which these devices contribute to the overall meaning of the texts. To achieve these goals, we formulated the following research questions: What cohesive devices are employed by the editors in creating editorial texts in the selected newspapers? What patterns of cohesion are found in the editorials? To what extent are cohesive devices utilized in the editorials of The Punch and Vanguard newspapers?

\subsection{Methodology}

Our data for analysis were purposively sampled from fourteen editorial comments of The Punch and Vanguard newspapers. The newspapers gathered from The Punch covered the period between July, 25, h and $29^{\text {th }}$ and August $5^{\text {, }}$ and $12^{\mathrm{lh}}, 2016$. Those gathered from Vanguard covered the period from July, $25^{111}$ to $29^{\text {th }}$ and August $1^{\mathrm{sl}}$ to $12^{\mathrm{lh}}, 2016$. The data enabled the researcher to review current, predominant and topical issues of the Nigerian society that reflect the use of English in various strata of the society.

Using Halliday and Hasan's concept of cohesion as the theoretical framework, we adopted both qualitative and quantitative analytical techniques to reveal how cohesive devices strategically work to create texts and enrich texture and meanings in editorial comments in the newspapers studied. With the use of tables, the frequency of cohesive devices found in the texts were shown as they occur in the editorials, aiming at highlighting the prominent roles played by the devices as well as portraying how some editorial texts construct the realities of the Nigerian society. Our choice of The Punch and Vanguard newspapers was informed by the fact that they are among the standard national dailies widely read in the country and that they are rich in terms of linguistic resourcefulness.

\section{Situating the Research}

Using various methods and approaches, several scholars have been examined the use of cohesive devices in texts and discourses. Halliday and Hasan's (1976) work has generally been considered the seminal work on the topic irrespective of the fact that Gitwinski's (1976) volume on textual cohesion was released a few months before theirs. Since then, there has been an emerging and continuous scholarly interest on cohesion in various respects.

Taboada (2000) investigated the anaphoric relations found in Spanish and English conversations showing how cohesive chains are clearly related to the generic stages in the dialogue as well as the measures of cohesive harmony in speech. The research concludes that lexical cohesions, specifically, the repetition of the same item, is most widely used followed by the use of reference, noting that both languages preferred anaphoric reference type. Again, Mirzapour and Ahmadi (2011) conducted a comparative study of lexical cohesions in English and Persian research articles in terms of number and degree of utilization of sub-types of lexical cohesion in order to appreciate textualisation processes in the two languages concerned. The study revealed that in terms of sub-types of lexical cohesion, the order of occurrence in descending order is: repetition, synonymy, collocation, antonymy, hyponymy, meronymy, general noun, among others and that in both sets of data, the most frequent sub-types are: repetition, collocation and synonymy. 
Alarcon and Morales (2011) considered grammatical cohesion in students' argumentative essay using Halliday and Hasan's (1976) concept of grammatical cohesion as the framework. The study concluded that certain cohesive ties assisted the students in the argumentation process. Similarly, Johnson (1992) examined the relationship of cohesion to overall writing quality of the text. In doing this, the amount and types of cohesive devices used in three groups of students' essays were correlated to the overall qualities rating of these essays given by the respective teachers of each group. It was established that there is no significant difference between the numbers of cohesive ties used to the overall quality of essays among the three groups. This implied that the students made adequate use of cohesive devices and this added to the overall quality of the texts.

Also, Crossley and Mcnamara (2010) examined the roles of cohesion and coherence in the evaluation of essay quality. They analysed the ratings of individual text features by experts including coherence, in order to examine their relation to evaluations of holistic essay quality. The result showed the fact that coherence is an important attribute of overall essay quality, except that expert raters evaluate coherence based on the absence of cohesive cues in the essays rather than their presence. On the contrary, Liu and Braine (2005) established a correlation between the frequency of cohesive devices and quality of writing, while Aghbam and Hadidi (2015) explored and explained the occurrence of two types of lexical cohesive devices: collocation and synonymy evident generally in both academic and news genres using mainly Halliday and Hasan's (1976) model of cohesion. The study reveals that the frequency and percentage of synonymous words are higher than collocational words in academic article whereas, in news genre, the frequency and percentage of collocational words are higher than synonymous words.

Uzodimma (2016) discussed aspects of cohesion in Chimamanda Adichie's Purple Hibiscus. Findings of the research revealed that there is a penchant for repetition of same-word lexical items and use of superordinate and metonymy in the text under study, and that although other referential devices were used to organize semantic information for effective communication, personal references of the anaphoric type, seemed to have been favoured.

Ashipu and Atsu (2013) examined the use of cohesive devices in Newswatch Magazine to achieve a meaningful whole for effective communication using Halliday and Hasan's (1976) theory of Cohesion. The analysis revealed that two major types of cohesion are mainly used on almost equal terms to achieve cohesion in the editorials. These are: reference and lexical cohesion.

It can be noticed from the reviewed studies the conspicuous gap with respect to research on the use of cohesion in the editorials of The Punch and Vanguard newspapers; hence, the necessity and justification for the present investigation.

\section{Theoretical Framework}

This work is anchored on Halliday and Hasan's (1976) model of cohesion. Although these scholars look into cohesion from various points of view, such as: textual or discourse structure, this study relies more on the application of grammatical and lexical cohesive devices as are employed by the editorial board of The Punch and Vanguard newspapers. Generally, scholars who have investigated the concept of cohesion usually offer their own categorization of cohesive devices, though often not dissimilar from that of Halliday and Hasan. For instance, Hu (1993) followed Halliday and Hasan's model but establishes four types of cohesion, namely: the referential, structural, logical and lexical cohesion. The author attempts a grouping of cohesive ties according to structural features of Chinese.

Taking insights from some of the progresses in the traditional model, Hu (1993) opined that cohesive relations can also be found in other categories like transitivity at the semantic level, the thematic structure and the syntactic level and intonation as well as sound patterns at the phonological level and concludes that textual cohesion and coherence can be analysed at various levels. In addition, Zhang and Liu (2003) equally extended the scope of cohesion to include cross-type cohesion, explicit cohesion and implicit cohesion, among others. They focus on the relationship between cohesion and coherence. The argument here is that interpersonal relations can also play an important role in creating cohesion and mood; modality and other devices which realise interpersonal meaning can also contribute to discourse cohesion and coherence.

Xi (2010:p139) rightly noted that at the moment "the best-known and most detailed model of cohesion available is that outlined by Halliday and Hasan" and the notion has been widely accepted as a useful tool for the analysis of text beyond the sentence level. For Halliday and Hasan (1976:p4), cohesion occurs "when the interpretation of some elements in the discourse is dependent on that of another". It is the linguistic means in existence for the creation of texture. Cohesive devices are properties of a text that make the text interpretable whole, rather than unconnected sentences. Yule (1996:p141) also observed that "analysis of these cohesive links within a text gives it some insights into how some writers structure what they want to say and may be crucial factors in our judgment on whether something is well written or not". This correlates with the view of Halliday and Hasan (1976) that the configuration of cohesion constitutes and defines a text and its texture. They refer to the linguistic devices that are used in relating different part of a text to another as, cohesive devices and argue 
that texts achieve their status as communicative events through the use of these cohesive devices. Cohesion contributes significantly to a text construction.

In Osisanwo (2003), cohesion is viewed as the linguistic means by which a text functions as a single unit. Olateju (2006) agrees that cohesion concerns how words in a text are related. Put differently, the concept denotes relation of meaning that exists within a text. Mirzapour and Ahmadi (2011) explained that cohesion expresses the continuity that exists between one part of the text and another one and that cohesion makes the interaction between the reader and the text possible because cohesive ties can help a reader to supply the missing points in a text even though the text is not complete. That is, even when a writer has omitted certain aspects of the text which ought to have been repeated. The richness of cohesive devices in a text contributes to clarity, readability and comprehensibility of the text to a large extent.

\section{Data Presentation and Analysis}

This section focuses on the presentation and analysis of data with respect to the different forms of lexical cohesion employed in the construction of editorial texts. The percentages of frequencies of the different lexical ties are highlighted below and further analysis is made on the various forms of lexical cohesive devices, mainly reiteration and collocation.

\subsection{Reiteration}

Here, the editors' utilization of lexical cohesive tool of reiteration is analysed in two stages. At first, the total number of lexical cohesive devices used in the texts as well as the total number of reiteration is presented in a tabular form. The second stage presents the number of occurrence of each type of cohesive devices used under reiteration and the total number of reiteration. This process arrives at a conclusion on the frequency of each of the cohesive ties of reiteration and determines the most frequently used ties of reiteration by the editors.

Table 4.1 presents the result of the frequency and percentage of reiteration in the texts under study.

Table 4.1: Lexical Reiteration Device

\begin{tabular}{llll}
\hline S/N & Items & Frequency & Percentage \\
\hline 1. & Lexical ties & 126 & $\mathbf{1 0 0 \%}$ \\
2. & Reiteration ties & $\mathbf{7 6}$ & $\mathbf{6 0 . 3 1 \%}$ \\
\hline
\end{tabular}

From the Table, it has been revealed that the editors adequately utilize the cohesive device of reiteration with the total percentage of $60.31 \%$ in the textual creation of the editorials studied. This demonstrates that the editors of both newspapers are fully aware of the effective role of this device in the development of the lexical structure of a text. Meanwhile, the various categories of reiteration found in the texts are portrayed below:

\subsubsection{Same-Word Reiteration}

Table 4.2 shows the spread of same-word reiteration within the texts studied as well as their percentage of occurrences as against the total number of cohesive devices of reiteration found in the texts.

\section{Table 4.2: Same-word Reiteration}

\begin{tabular}{llll}
\hline S/N & Items & Frequency & Percentage \\
\hline 1. & Total Number of Reiteration & $\mathbf{7 6}$ & $\mathbf{1 0 0 \%}$ \\
$\mathbf{2}$ & Total Number of Same-word Repetition & $\mathbf{7 1}$ & $\mathbf{2 2 . 3 7 \%}$ \\
\hline
\end{tabular}

It is apparent from Table 4.2 that the editors make predominant use of this device in the texts to recast ideas earlier discussed in the texts.

\subsubsection{Synonymy}

Table 4.3 reflects on the frequency and percentage of repetition through the use of synonyms within the texts.

Table 4.3: Synonyms

\begin{tabular}{llll}
\hline S/N & Items & Frequency & Percentage \\
\hline 1. & Total Number of Reiteration & 76 & $\mathbf{1 0 0 \%}$ \\
2. & Total Number of Synonym & 71 & $\mathbf{2 2 . 3 7 \%}$ \\
\hline
\end{tabular}

The presentation on Table 4.3 reveals that synonyms are sparingly used in the construction of the texts studied as compared to the frequency of same-word repetition which has a higher percentage of $76.31 \%$.

\subsubsection{General-word Repetition}

The frequency and percentage of general-word repetition found in the texts are presented in the Table 4.4.

\section{Table 4.4: General-word Reiteration}

\begin{tabular}{llll}
\hline S/N & Items & Frequency & Percentage \\
\hline 1. & Total Number of Reiteration & $\mathbf{7 6}$ & $\mathbf{1 0 0 \%}$ \\
$\mathbf{2}$ & Total Number of General-word Reiteration & $\mathbf{1}$ & $\mathbf{1 . 3 1 \%}$ \\
\hline
\end{tabular}

General-word reiteration has the least percentage of occurrences of just $1.31 \%$ throughout the texts studied. 


\subsection{Collocation}

The frequency and percentage of collocation based on the total frequency and percentage of all the lexical cohesive devices in the texts are presented in Table 4.5.

Table 4.5: Collocation

\begin{tabular}{llll}
\hline S/N & Items & Frequency & Percentage \\
\hline 1. & Total Number of Lexical Cohesive Devices & 126 & $\mathbf{1 0 0 \%}$ \\
2. & Total Instances of Collocation & $\mathbf{5 3}$ & $\mathbf{4 2 . 0 6 \%}$ \\
\hline
\end{tabular}

Table 4.5 demonstrates that the editors utilize the collocation strategy in their textual creation. They show mastery of the English lexicon and the company words could keep in binding ideas together within texts.

\section{Discussion of Findings}

This segment is devoted to the discussion of findings in the two categories of cohesion, reiteration and collocation, deployed in the editorial creation. This serves to highlight the extent to which the texts are knitted together with the different lexical cohesive devices available in English language for use in the construction of the texts.

\subsection{Reiteration}

From the results presented on Tables $4.1-4.4$, we observed that reiteration is the most frequently used lexical cohesive device in editorial texts of The Punch and Vanguard newspapers studied. Although collocation has been used extensively too in the texts, reiteration gains prominence in terms of frequency and percentage.

Of the forms of reiteration, same-word repetition gained prominence in frequency and percentage. Uzodimma (2016) also observed this penchant for same-word repetition by writers in textual construction. This is due to the fact that such reiteration plays a vital role in keeping track of the subject matter unambiguously. It serves to emphasize and remind readers of the central ideas discussed by writers. For instance, most of the instances of same-word repetition in the texts studied had to do with the subject of discussion. In text $\mathbf{3}$, for example, the expression 'the $N F F^{\prime}$ ' mentioned at first in sentence 5 of the text has been reiterated 7 times in subsequent sentences for emphasis without any ambiguity.

Again, in text 4, 'the IOC' has been repeated 6 times within the same text. Similarly, the lexical item 'Athletes' has been mentioned 6 times within text 4. 'Recession' has been repeated 4 times in text 5. 'The CBTT in text 8 has been reiterated 3 times, among others.

All these instances of reiteration pointed to the subject matter of the texts. For example, the subject matter of text 3 is 'Needless Fuss over Foreign Coach'. The editors lay emphasis on the inability of the Nigerian Football Federation (NFF) board to recruit a new coach, whether foreign or local. In text 4, the focus is on the band athletes from Olympic Games over the use of banned drugs. Text 5 deals with 'Navigating Nigeria out of Recession ', while text 8 focuses on 'Attracting Foreign Investors to the Forex Market'. All of these subject matters brought about the repetition of relevant linguistic units. Such repetitions are very significant in editorial texts as they foreground the central ideas in most instances. The continuous repetition of such items keeps the readers focused on the subject matter under discussion. In stressing the important place of same-word reiteration in textual development, Jabeen, Qasim and Nawaz (2014:p107) explained that repetition of the same lexical items within a text "also highlights their significant place in the overall lexical stock of the texts and renovates their meaningful part in portraying the thematic outlook of the texts."

Although synonymy was used by editors in the texts, its use was very minimal with the total percentage of $22.37 \%$. This is consciously done in order to reduce the rate of ambiguity. Among the primary aims of editorial comments is communication (Anim, 1996). Over-use of synonyms increases the risk of ambiguity on the part of the reader, thereby distorting meaning comprehension. This is because, the reader may not readily have a suitable interpretation of what the synonym used at a particular instance depicts.

In text 11 sentence 1 for instance, we have:

The recent announcement by the Finance Minister,

Mrs. Kemi Adeosun, that the economy is now technically in recession

did not surprise stakeholders

but in sentence 2 we have:

Even the central bank of Nigeria (CBN) has repeatedly affirmed that the economy has been sinking... We observe that the lexical item 'recession' and 'sinking' in the examples above are in synonymous relationship to each other. Apart from proximity of occurrence, which helps a lot in meaning interpretation, it takes a mental work to associate recession with sinking ordinarily. In order to be apt in communication, the editors preferred same-word repetition to synonyms.

\subsection{Collocation}

Results from the texts presented in previous sections demonstrated that editors took cognizance of the invaluable 
role of cohesive ties of collocation. They showed familiarity with the subject matters discussed by employing lexical items within the field of discourse to pass their messages across to readers. They recognised the company that words keep by using suitable words. Aghdam and Hadidi (2015) agreed to the salient presence of collocation particularly in the news genre. This is because collocation does not only enhance textuality in discourse through its connectivity but it as well gives insight to the subject matter. For instance, the following collocates in text 1:

System
Banks
Accounts
Loans
Collaterals

and points back to the subject matter which bothers on the CBN strengthening the banking system. Similarly, in text 3, the following collocates:

Coach

Gaffer

African Nations Cup

Tournaments

Training Centers

and calls to mind the subject matter which has to do with 'football' or 'sports'.

Again, in text 14, lexical items such as:

\section{Mothers}

Exclusive

Newborns

Babies

Infant

Children

Breastfeeding

are employed in talking about 'Nigeria's Slow Drive in Exclusive Breastfeeding' as the subject matter.

\section{Conclusion}

The paper has analysed the patterns, types, frequency and roles of cohesion deployed by the editors of The Punch and Vanguard newspaper of Nigeria. Two main types of cohesion were found in the editorial commentaries, viz reiteration and collocation. The quantitative analysis revealed that same-word repetition had the highest percentage $(22.37 \%)$ of deployment in the editorial creation, while general-word reiteration type was least deployed in the texts studied, with only $1.31 \%$. In the case of collocation device, its usage amounted to $42.06 \%$.

In line with our goal, the paper has revealed how cohesive devices have worked to aid textual creation and meaning comprehension. The device of cohesion contributed to the overall meaning and points of emphasis by binding words and ideas together, thus enhancing a sense of connection and flow of thoughts within the editorial texts, thereby accentuating the agglutinating effects of cohesive devices as theorized by Halliday and Hassan(1976).

It is logical to conclude that for a text to be cohesive and coherent, it must held together by some cohesive devices. However, we recommend that further investigation on other standards of textuality in both literary and non-literary texts be carried out.

\section{REFERENCES}

Aghdam, S. H and Hadidi, Y. (2015). Cohesion and coherence in political newspapers and discussion sessions of academic articles. International Journals on Studies in English Language and Literature. 3(3): 1122.

Alarcon, J. B. and Morales, K. N. S. (2011). Grammatical cohesion in students' argumentative essay. Journal of English and Literature, 2 (5): 114127.

Ashipu, K. and Atsu E. (2013). Cohesive devices in Nigerian media discourse: A study of Newswatch Magazine, p9. In: A. Emenyi. (Editor) A Journal of Research in Nigerian English and Literature: In Honour of Prof. David Eka. EXofta. Media Service Ltd., Uyo.

Bloor, T. and Bloor, M. (2004). The Functional Analysis of English: A Hallidayan Approach. 2nd edition. Oxford University Press Inc, New York, 315p.

Crossle, S. and McNamara, D. (2010). Cohesion, coherence and expert evaluation of writing proficiency. In: Conference Proceedings at the $32^{\text {nd }}$ Annual Conference of the Cognitive Science Society.

Esimokha, G. (2011). Newspaper \& Magazine: Editing, Production and Marketing. Great Achievers Communications, Lagos. 
Gitwinski, W. (1976). Cohesion in Literary Text: A Study of Some Grammatical and Lexical Features of English Discourse. Mouton, The Hague, 183p.

Halliday, M. and Hasan, R. (1976). Cohesion in English. Longman, London, 374p.

Hameed, H. (2008). Cohesion in text: A discourse analysis of news article in a magazine. Al-Faith Journal, $37,81101$.

Hu, S. Z. (1993). Comparative Studies in English and Chinese Rhetoric. Shanghai Foreign Language Education Press, Shanghai.

Kaleta, Z. K. (2012). The discourse of television news programs as a means of influencing public opinion - an analysis based on the CDA. Media SPOLECZENSTWO, 3:29-39

Liu, M. and Braine, D. (2005). Cohesive Features in Argumentative Writing Produce for Chinese Undergraduates. http.//www.sciencedirect.com/scien. (Retrieved on 15th December 2016).

Maale, Z.(1015). Persuasion in the discourse of billboards: A stylistic account. Researchgate . http//www.researchgate.net. (Retrieved on $17^{\text {th }}$ July)

McCabe, A. and Heilman, K. (2007). Textual and interpersonal differences between a news report and an editorial. Ife Studies in English Language, 20 (7): 139156.

Mirzapour, F. and Ahmadi, M. (2011). Study on lexical cohesion in English and Persian research articles. English Language Teaching,4(4):245 253.

Montejo, G. M. and Adriano, T. Q.(2018). A critical discourse analysis of headlines in online news portals. Journal of Advances in Humanities and Social Sciences, 4(2): 70-83

Olaniyan, K. (2011) Cohesion and coherence in editors' comments in Tell Ma Studies in English Language, 5, 12-21.

Olateju, M. A. (2006). Cohesion in ESL classroom written texts in Nordic. Journal of African Studies, 15(3): 134-331.

Osisanwo, W. (2003). Introduction to Discourse Analysis and Pragmatics. Fatnulous Fetop Publishers, Lagos, $130 \mathrm{p}$.

Paltridge, B. (2006). Discourse Analysis. Continuum International Publishing Group, London and New York, $256 \mathrm{p}$.

Schaffner, C.(2010). Editorial: political speeches and discourse analysis. Current Issues in Language and Society, 3(3): 201-204

Tabe, C.A. and Fieze, N.I. (2018). A critical discourse analysis of newspaper headlines on the Anglophone crisis in Cameroon. British Journal of English Linguistics. 6(3): 64-83.

Taboada, M. (2000). Cohesion as a measure in generic analysis. Circle of Linguistics Applied to Communication. 3 (35): 66-70

Uzodimma, J. (2016). Aspects of cohesion in Chimamanda Adichie's Purple Hibiscus. Papers in English and Linguistics. 17(1 ):273-300.

Wang, Y. and Quo, M. (2014). A short analysis of discourse coherence. Journal of Language Teaching and Research, 5 (2): 460-465.

Xi, Y. (2010). Cohesion studies in the past 30 years: Development, application and chaos. The International Journal - Language Society and Culture. 31, 139-147.

Yule, G. (1996). The Study of Language, 2nd Edition. Cambridge University Press. New York, 308p.

Zhang, D. L. and Liu, R. S. (2003). The Development of the Theory of Text Coherence and Cohesion and its Application. Shanghai Foreign Language Education Press, Shanghai, 314p. 